\title{
Reevaluation of Host Specificity of the Closely Related Species Pseudoperonospora humuli and $P$. cubensis
}

Fabian Runge, University of Hohenheim, Institute of Botany 210, D-70593 Stuttgart, Germany; and Marco Thines, Biodiversity and Climate Research Centre (BiK-F), D-60325 Frankfurt (Main), Germany, Senckenberg Gesellschaft für Naturforschung, Senkenberganlage 25, D-60325 Frankfurt (Main), Germany, and Johann Wolfgang Goethe University, Department of Biological Sciences, Institute of Ecology, Evolution and Diversity, D-60325 Frankfurt (Main), Germany

\begin{abstract}
Runge, F., and Thines, M. 2012. Reevaluation of host specificity of the closely related species Pseudoperonospora humuli and P. cubensis. Plant Dis. 96:55-61.

Pseudoperonospora cubensis causes some of the most devastating diseases of cucurbitaceous crops, while $P$. humuli is an important pathogen of hop (Cannabaceae). Although parasitic to different Angiosperm orders, these pathogens are highly similar, both in morphology and based on molecular comparisons. Considering the close relationship of $P$. humuli and $P$. cubensis, it was hypothesized that cross infectivity of the pathogens between their optimum hosts might be possible. Two strains of $P$. humuli and one of $P$. cubensis used in this study were able to reproduce on the two wild cucurbit relatives Bryonia dioica and Sicyos angulatus. Interestingly, limited infectivity of the P. cubensis strain to hop was also observed, and the P. humuli

were verified by comparing the nuclear ribosomal-internal transcribed spacer sequences of newly produced sporangiophores from the different hosts. Morphologically the two pathogens could be distinguished by statistical analyses on their original hosts but these differences diminished on some alternate hosts. The ability of $P$. cubensis to infest the perennial Bryonia dioica and Humulus lupulus might offer a limited possibility for overwintering in temperate regions and needs to be evaluated in future studies. The ability of $P$. humuli to complete its life cycle on all the tested cucurbits provides evidence that the host jump across orders may continue and points to the high virulence potential of this pathogen.
\end{abstract} strain was also able to infest Cucumis sativus. The cross infections
The monophyletic genus Pseudoperonospora is distributed worldwide and includes six accepted species, parasitizing host plants belonging to the families Balsaminaceae, Cannabinaceae, Cucurbitaceae, Fabaceae, Ulmaceae, and Urticaceae $(26,52,53)$ The economically most important species are Pseudoperonospora humuli and P. cubensis. Downy mildew of hop caused by $P$. humuli occurs in all of the hop-growing countries of the northern hemisphere and in Argentina (35). P. humuli overwinters as mycelium in the rhizome of hop (39). These persistent infections originate from secondary infections of basal spikes, from which the mycelium grows downward to the perennial rhizome $(10,43)$ which, therefore, is the main source of the primary infections every year. Although formed abundantly in diseased hop tissues, oospores are reported to be of minor importance for the persistence of the pathogen $(24,35,43)$. Downy mildew of cucurbits caused by $P$. cubensis occurs throughout the world on wild and cultivated Cucurbitaceae species and wherever cucurbits are grown $(8,22)$. More than 60 host species have been reported $(27,28)$, including all cucurbits of economic interest. In warm temperate to subtropical regions without frost events, $P$. cubensis overwinters as active mycelium in the tissue of its host $(2,22)$. In colder regions where cucurbit plants die back in autumn, this mode of overwintering is not available to the pathogen and hibernating oospores of $P$. cubensis seem to be very rare. This gives rise to a widely accepted theory, stating that primary infections in northern latitudes are the result of the annual long-range dispersal of spores from subtropical regions (21). However, the recent discover by Cohen et al. (9) that oospores could be formed abundantly when two compatible strains

Corresponding author: M. Thines,

E-mail: Marco.Thines@senckenberg.de

Accepted for publication 29 July 2011.

http://dx.doi.org/10.1094/PDIS-01-11-0035

(C) 2012 The American Phytopathological Society are brought together is challenging this view, despite the rare observations of oospores in field samples.

The four species, $P$. cannabina, $P$. humuli, $P$. celtidis, and $P$. urticae, parasitizing members of the Rosales s.l. (Cannabaceae, Ulmaceae, and Urticaceae), not only are similar in morphological characteristics $(12,53)$ but also their hosts are closely related $(3,4,44,45)$. Earlier investigations have revealed that $P$. cubensis, despite parasitizing the only distantly related Cucurbitaceae family, is closely related to $P$. humuli $(5,11,16,31,36)$. The only slight morphological differences (53) make it difficult to distinguish these species and, thus, distinction is mostly done on the basis of the host plant affected (5). A taxonomic revision of downy mildews in Korea (42) based on morphological characteristics indicated that $P$. cubensis and $P$. humuli might be conspecific. However, molecular genetic analysis of Runge et al. (36) revealed that, based on nrinternal transcribed spacer (ITS), cox2, and ypt 1 sequences, $P$. cubensis and $P$. humuli are distinct species, which is also corroborated by a recent study of Mitchell et al. (31). However, they stated in the abstract that the $P$. cubensis cluster contained $P$. humuli, and that the latter species could have descended from the former, which is not supported by the trees presented in their study, because all trees showed a polytomy for the placement of $P$ cubensis in relation to $P$. humuli. However, Runge et al. (36) obtained support for a basal position of $P$. humuli, thereby providing evidence for a recent host shift from Cannabinaceae to Cucurbitaceae, because two linages of Pseudoperonospora parasitic on Humulus spp. (Cannabinaceae) were consistently placed basal to Pseudoperonospora lineages parasitic to members of Cucurbitaceae.

Although $P$. cannabina, $P$. celtidis, and $P$. urticae are phylogenetically distinct from $P$. humuli $(5,36)$, the latter pathogen is able to infest the hosts of the former species $(19,21,40,41)$. However, very little data is available for cross-inoculation experiments for hosts of $P$. cubensis and P. humuli (21), and contemporary with this study has a single successful transfer based on a single sporangiophore been reported (31), although without molecular confirmation of the pathogen. Despite the close relationship of $P$. humuli and $P$. cubensis, no further reports concerning a possible overlap in the 
potential host ranges of these pathogens are available and thus are not well resolved. The question arises whether cucurbit-infecting downy mildew might be able to infect hop, with the potential risk that $P$. cubensis could overwinter in northern regions in this perennial host. In addition, if $P$. cubensis and $P$. humuli may parasitize the hosts of the other species, it might be possible that some limited gene flow might still exist, which could give rise to new pathotypes with altered virulence. Therefore, it was the aim of this study to clarify whether there is still the possibility of some bidirectional infection on the hosts of the other species.

\section{Materials and Methods}

Infection experiments were carried out using the $P$. cubensis strain P.C. 26/01 that originated from the Olomouc Region of the Czech Republic, and a $P$. humuli strain that originated from the Botanical Garden of the University of Hohenheim. The isolates were maintained in climate chambers $\left(16^{\circ} \mathrm{C}, 14 \mathrm{~h}\right.$ of light, and $10 \mathrm{~h}$ of darkness) on Cucumis sativus 'Chinese Slangen' and H. lupulus (wild), respectively. Infections were done using a dab-off technique as described previously $(37,38)$. Fully mature leaves of Bryonia dioica, $C$. sativus, Sicyos angulatus, and $H$. lupulus were taken from plants grown in semicontrolled greenhouses $\left(16\right.$ to $24^{\circ} \mathrm{C}$ and a 14-h lighting period) at the University of Hohenheim; leaves of $S$. angulatus were cut outdoors (from the Botanical Garden of the University of Hohenheim). Inoculation experiments were repeated 25 times for $C$. sativus and $B$. dioica with $P$. humuli and for $H$. lupulus with $P$. cubensis, 50 times for $B$. dioica with $P$. cubensis, and 5 times for $S$. angulatus with each pathogen. In each replicate, 3 to 6 leaves, depending on the availability of suitable plant material, representing the 5th to 10th leaves from the apex, were used. Inoculation of detached leaves was given preference over leaf discs, because the latter are prone to artifacts whereas detached leaves offer the possibility of much less bias, due to a comparable infection process and little wounding stress. After inoculation, the leaves were transferred to transparent boxes (approximately $30 \mathrm{~cm}$ long, $20 \mathrm{~cm}$ wide, and $5 \mathrm{~cm}$ high) on water-soaked paper towels to ensure that $100 \%$ relative humidity was maintained within the boxes. When the first sign of sporulation could be observed, single sporangiophores protruding from stomata were picked from sporulating leaves with precision tweezers under a stereomicroscope, and each picked sporangiophore was transferred to a reaction tube containing polymerase chain reaction (PCR) reaction mix, with the primers LR-0 (reverse complement to LR-0R, described by Moncalvo et al.; 32) and DC-6F (13) for amplifying nrITS. PCR reactions were carried out as described earlier (48). Sequencing was done by a commercial sequencing company (GATC-Biotech, Germany) and sequence alignment was performed using MEGA (46), version 4.0, which is feasible, because ITS sequences for the $P$. cubensis species complex contain neither insertions nor deletions.

Two days later, close-up photographs were taken using an Olympus SK60 stereomicroscope (Olympus, Hamburg, Germany) with a Schott KL1500 illumination unit (Schott, Mainz, Germany) and fully mature sporangiophores with sporangia were picked from the leaf surface with precision tweezers. Some of them were transferred to water drops on leaves of the original hosts for back-infection experiments, while others of the sporangiophores with sporangia were transferred to a drop of water on a microscopic slide and covered with a coverslip. The morphology of sporangia and sporangiophores were investigated using a Biomed (Leitz, Wetzlar, Germany) light microscope. Pictures were taken using a Canon PowerShot A640 photocamera (Canon, Tokyo). Before each picture series, a picture of a stage micrometer was taken to calibrate the measurements which were conducted with the AxioVision LE software (Carl Zeiss Imaging Solutions, München, Germany). The characteristics examined were the length of the sporangiophores $(n$ $=25)$, the height of the first ramification $(n=25)$, the width of the trunk $(n=25)$, the length of the dichotomous ultimate branchlets ( $n=50$ each for shorter and longer branchlets), and the length and the width of the sporangia ( $n=100$ each). The ratio of the length of the sporangiophores to the relative height of the first ramification for each sporangiophore, the ratio of the longer to the shorter ultimate branchlets of each dichotomous ultimate ramification, and the ratio of length to width of the sporangia for each individual sporangium were calculated. Afterward, the data were statistically analyzed using STATISTICA '99 (StatSoft, Tulsa, OK). The Mann-Whitney U test (30) was applied for investigating the significance of the differences between the species investigated.

For scanning electron microscopy, pieces $(5$ by $5 \mathrm{~mm}$ ) of the parasitized areas were cut from the leaves and were put upside down in a desiccator to dehydrate the samples for 2 days. After dehydration, the samples were gold/palladium (80:20) coated in a Balzers Union SCD040 (Balzers, Trübbach, Schweiz) sputtering device and examined using a Zeiss DSM940 scanning electron microscope (Zeiss, Wetzlar, Germany) as described previously (47).

\section{Results}

At 4 to 10 days after inoculation, sporulation was observed on the lower surface of the leaves (Fig. 1). Positive controls (P. cubensis on $C$. sativus and $P$. humuli on $H$. lupulus) always yielded infection and negative controls (leaves without inoculum) never showed sporulation. P. cubensis infected B. dioica in 42 of 50 trials, $H$. lupulus in 6 in 25 trials, and $S$. angulatus in 4 of 5 trials. $P$. humuli infected $B$. dioica in 16 of 25 trials, $C$. sativus in 7 of 25 trials, and $S$. angulatus in 3 of 5 trials. Symptoms of $P$. humuli and $P$. cubensis were almost identical on $B$. dioica. Also, on $S$. angulatus, there were no differences of the symptoms for both pathogens. On $B$. dioica, round chlorotic to necrotic spots could be observed for both pathogens but the number of spots caused by $P$. cubensis was higher compared with the number of spots caused by $P$. humuli. The sporulation was dense on leaves of B. dioica (Fig. 1E), with the result that the infection spots were exhibiting a blackish color. In the case of $S$. angulatus, the sporulation was restricted to few areas. However, on these areas, the sporulation was very strong (Fig. $1 \mathrm{G})$ and, therefore, appeared floccose and dark gray in color. On $C$. sativus, the native host of the $P$. cubensis strain, sporulation of $P$. cubensis occurred on almost the whole lower leaf surface and some parts were densely covered, resulting in a downy and grayish appearance. Sporulation of $P$. humuli on $C$. sativus also occurred on the whole lower surface but sporangiophores stood isolated or in small groups, resulting in a normal to very light grayish appearance of the leaves. On $H$. lupulus, the native host of $P$. humuli, sporulation of $P$. humuli occurred mainly in the angles of the leaf veins but also in spots on the whole leaf surface and these areas were densely covered, resulting in a downy and dark grayish appearance. Sporulation of $P$. cubensis on $H$. lupulus was very sparse; only a few single sporangiophores or small groups of sporangiophores were present on the lower leaf surface. These sporangiophores were malformed (Fig. 2). Due to the sparse sporulation of $P$. cubensis on $H$. lupulus, no comprehensive measurements could be taken. The available sporangiophores were used for back infections and scanning electron microscopy. Back-infection experiments from all experimental hosts back to the original hosts were successful at least once.

Sequences of nrITS obtained from single sporangiophores were compared with sequences obtained from sporangiophores taken from the identical isolates used for cross-infection experiments. Sequence comparison revealed that the sporangiophores of $P$. cubensis and $P$. humuli picked from the other hosts were identical with those picked from the original hosts. ITS sequences of $P$. cubensis and $P$. humuli could be distinguished by four singlenucleotide polymorphisms (SNPs) in the whole nrITS sequence encompassing 802 bp (0.5\%; Fig. 3). The four SNPs are localized at base-pair positions 38 (ITS1), 455, 638, and 714 (ITS2). Sequence data of both strains had been surveyed by Runge et al. (35) and are available at GenBank under accession numbers HM636042 for nrITS of $P$. humuli and HM636033 for nrITS of P. cubensis.

The morphological characteristics are listed in Tables 1 and 2. $P$. humuli on $H$. lupulus and $P$. cubensis on $C$. sativus can be clearly distinguished on their native hosts. Out of the 10 characteristics 
investigated, 1 characteristic shows weakly significant $(P<0.05)$ differences, 1 characteristic shows significant $(P<0.01)$ differences, and 5 characteristics show highly significant $(P<0.001)$ differences. Only two characteristics are statistically not different $(P \geq 0.05)$. P. humuli on B. dioica and $P$. humuli on H. lupulus is the only pair with no statistically supported differences compared with each other. All other combinations have at least three characteristics significantly divergent at different $P$ levels.

In the analysis of the length of the sporangiophores, two groups are apparent. One includes $P$. humuli on $C$. sativus, $H$. lupulus, and

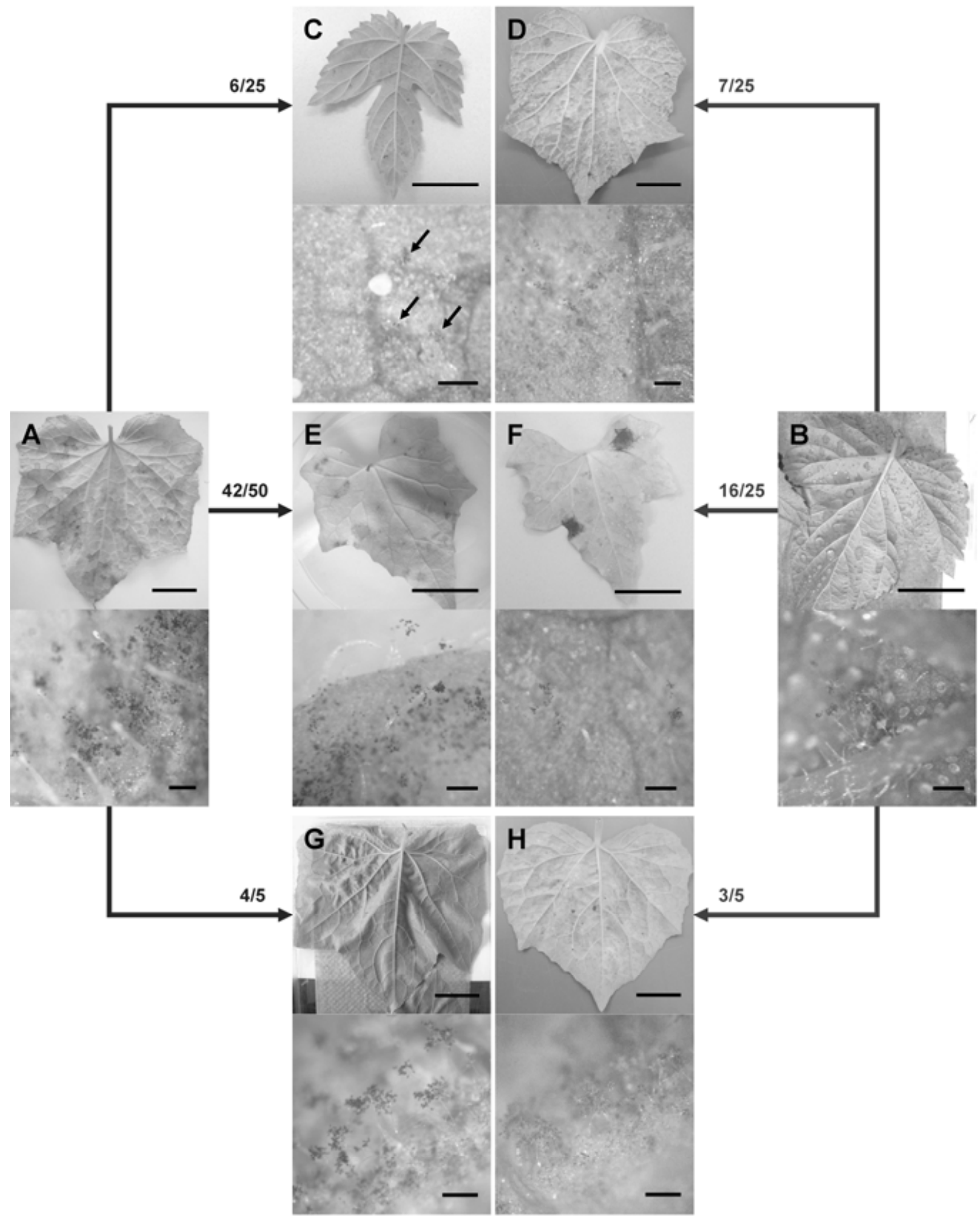

Fig. 1. Leaves of A, Cucumis sativus; C, Humulus lupulus; E, Bryonia dioica; and G, Sicyos angulatus infected with Pseudoperonospora cubensis, and leaves of B, $H$. lupulus; D, C. sativus; F, B. dioica; and H, S. angulatus infected with P. humuli. Bars in the close-up figures: $250 \mu \mathrm{m}$; bars in the leaf figures: $25 \mathrm{~mm}$; numbers above the arrows: number of successful infections/number of trials. 
B. dioica, with mean sporangiophore lengths $(n=25)$ of 251,253 , and $262 \mu \mathrm{m}$, respectively, and no significant differences compared with each other. The second group includes $P$. cubensis on $C$. sativus, B. dioica, and $S$. angulatus, with mean lengths of 325, 365, and $407 \mu \mathrm{m}$ respectively. The first group also includes $P$. humuli on $S$. angulatus $(295 \mu \mathrm{m})$, which is weakly significantly $(P<0.05)$ different from $P$. humuli on $B$. dioica and not significantly different from $P$. cubensis on $C$. sativus but shows a highly significant divergence from $P$. cubensis on $S$. angulatus. $P$. cubensis on $B$. dioica from the second group has no significant differences compared with $P$. cubensis on other hosts but highly significant differences compared with $P$. humuli on $B$. dioica. In the height of the first branching, $P$. humuli forms a homogenous group with mean values ( $n=25)$ ranging from $183 \mu \mathrm{m}$ on $C$. sativus to $203 \mu \mathrm{m}$ on $S$. angulatus. $P$. cubensis on $C$. sativus shows weakly significant differences to P. humuli on S. angulatus and on B. dioica $(199 \mu \mathrm{m})$. In contrast to the lengths of the sporangiophores and the heights of the first branching, the ratio of these characteristics shows significant differences between both species only on $S$. angulatus. $P$. humuli on $C$. sativus is similar to $P$. cubensis on $C$. sativus (1.38 and 1.41 , respectively, mean, $n=25)$ but it is different $(P<0.05)$ from $P$. humuli on $H$. lupulus $(1.31$, mean). In the width of the trunk, $P$. humuli on $C$. sativus $(4.20 \mu \mathrm{m}$, mean, $n=25)$ is different to a highly significant degree from both $P$. humuli on $H$. lupulus $(4.89 \mu \mathrm{m})$ and $P$. cubensis on $C$. sativus $(5.34 \mu \mathrm{m}) . P$. humuli has the thickest trunk $(5.81 \mu \mathrm{m})$ on $S$. angulatus, whereas $P$. cubensis has the thinnest trunk $(4.01 \mu \mathrm{m})$ on the same host.

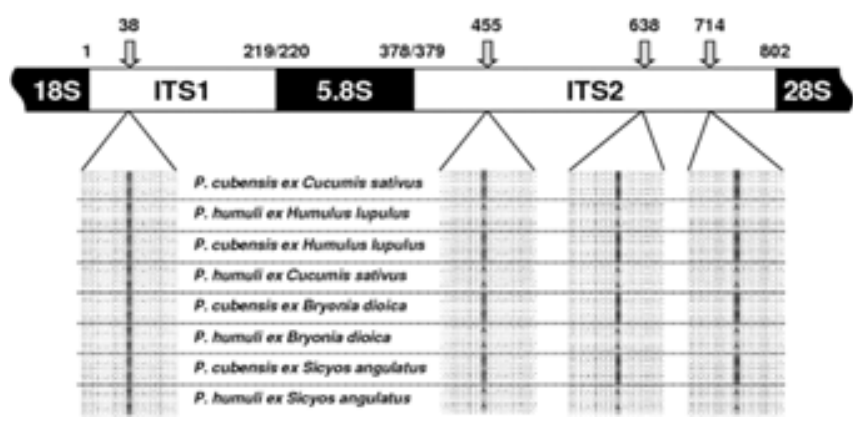

Fig. 3. Sequence alignment of the nr-internal transcribed spacer (ITS) sequences of Pseudoperonospora cubensis and $P$. humuli sporangiophores picked from different hosts. Numbers above the DNA strand indicate nucleotide positions in the nrlTS sequence. Arrows indicate diagnostic single-nucleotide polymorphisms in the nrlTS sequence.

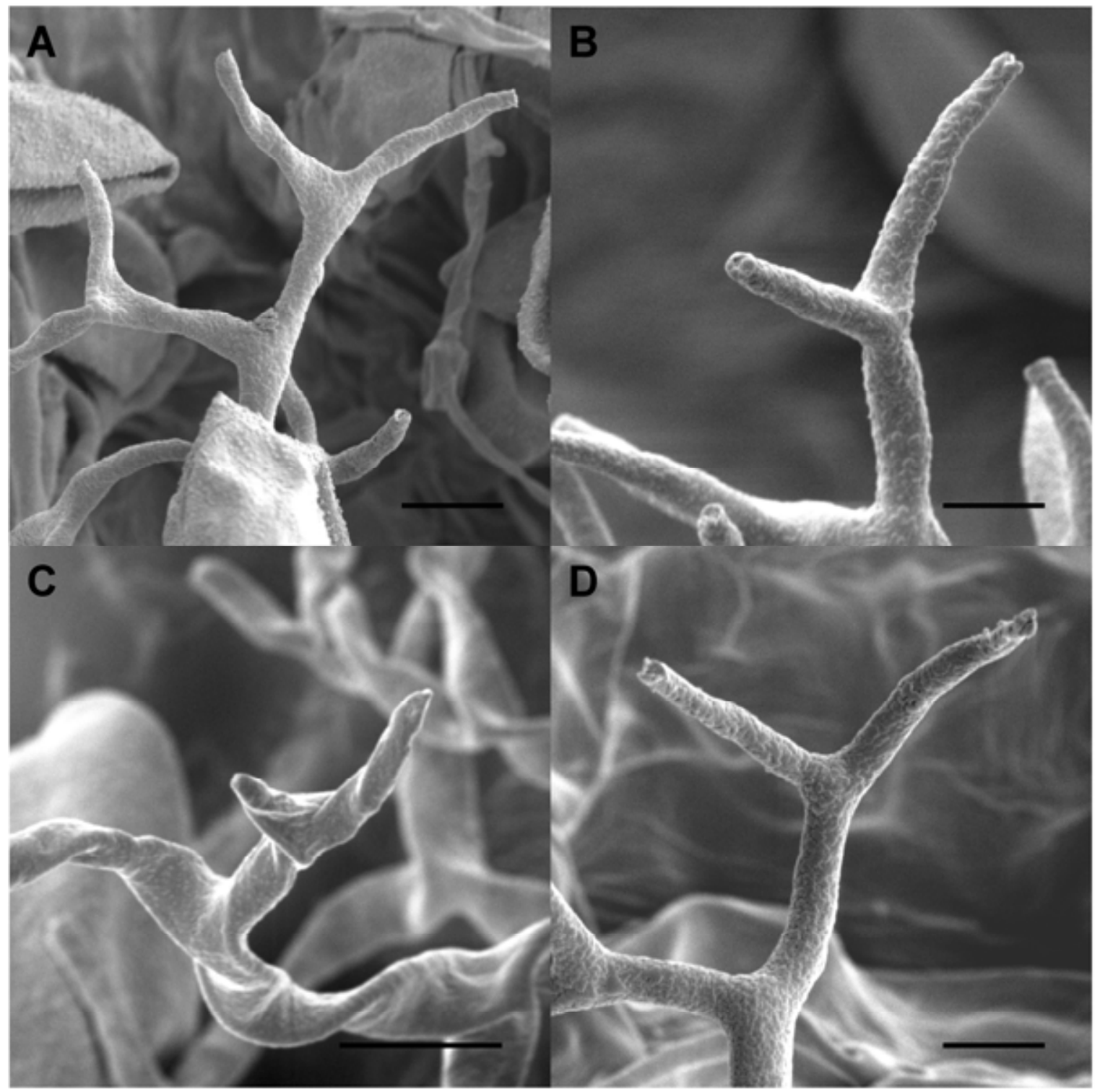

Fig. 2. Ultimate branchlets of the sporangiophores of $\mathbf{A}$, Pseudoperonospora cubensis. on Cucumis sativus and $\mathbf{B}, P$. humuli on Humulus lupulus. $\mathbf{C}, P$. cubensis on $H$. lupulus is collapsing due to thin walls, while $\mathbf{D}, P$. humuli on $C$. sativus is similar to $P$. humuli on $H$. lupulus. Bars: $5 \mu \mathrm{m}$. 
In ratio of the longer to the shorter ultimate branchlet, $P$. humuli on $C$. sativus $(1.20$, mean, $n=50)$ is dissimilar to $P$. humuli on $H$. lupulus (1.28) and to P. cubensis on C. sativus (1.32). In the case of $B$. dioica, $P$. humuli is dissimilar to $P$. cubensis, with weak significance in the lengths of the longer ultimate branchlets (11.8 and $10.4 \mu \mathrm{m}$, respectively; mean, $n=50$ ). However, in lengths of the shorter ultimate branchlets ( 9.37 and $8.49 \mu \mathrm{m}$, respectively) and in longer to shorter ratio (1.27 and 1.24, respectively), no significant differences are obvious. On $S$. angulatus, both pathogens are identical.

The sporangia of $P$. humuli on $C$. sativus measure $21.6 \mu \mathrm{m}$ in length (mean, $n=100$ ) and $15.2 \mu \mathrm{m}$ in breadth (mean, $n=100$ ), the length to breadth ratio being 1.43 (mean, $n=100$ ). This is identical in shape to $P$. cubensis on $C$. sativus $(24.8 \mu \mathrm{m}, 17.4 \mu \mathrm{m}$, and 1.43 , respectively) but dissimilar to $P$. humuli on $H$. lupulus $(23.7 \mu \mathrm{m}, 15.0 \mu \mathrm{m}$, and 1.59 , respectively). On B. dioica, P. humuli (24.1 $\mu \mathrm{m}, 15.0 \mu \mathrm{m}$, and 1.61, respectively) is similar to $P$. humuli on $H$. lupulus. But P. cubensis $(23.6 \mu \mathrm{m}, 15.7 \mu \mathrm{m}$, and 1.51, respectively) is similar in length to $P$. humuli on $H$. lupulus and $B$. dioica and similar in breadth to $P$. humuli on $C$. sativus and $P$. cubensis on $S$. angulatus. Sporangia of both species are markedly smaller on $S$. angulatus than on their original hosts but $P$. humuli (21.6 $\mu \mathrm{m}, 13.8 \mu \mathrm{m}$, and 1.56, respectively) is similar in shape to $P$. humuli on $H$. lupulus and $B$. dioica, whereas $P$. cubensis $(22.1 \mu \mathrm{m}$, $15.6 \mu \mathrm{m}$, and 1.41 , respectively) on this host is similar in shape to $P$. cubensis on $C$. sativus. However, P. cubensis on both $S$. angulatus and $C$. sativus are significantly different from
$P$. cubensis on $B$. dioica. All together, sporangia of $P$. cubensis were rounder in shape than sporangia of $P$. humuli on the respective hosts.

\section{Discussion}

The cross-infectivity of the two strains of $P$. cubensis and $P$. humuli used in this study and the infection experiments carried out in a parallel study of Mitchell et al. (31), which we were made aware of during the revision of this manuscript, revealed that the $P$. cubensis/P. humuli complex represents very closely related species. This hypothesis is also corroborated by recent phylogenetic investigations $(5,31,36)$. Waterhouse and Brothers (53) mentioned that, under natural conditions, $P$. urticae could only parasitize Urtica, $P$. cannabina could only infest Cannabis, and $P$. celtidis could only infest Celtis spp. Conversely, Hoerner (21) could artificially infect Cannabis, Celtis, and Urtica spp. with P. humuli and, therefore, suggested that the pathogens of the respective hosts could be races of the same species. Molecular phylogenetic investigations of Choi et al. (5) and Runge et al. (36) have revealed that these Pseudoperonospora spp. parasitic to members Rosales are clearly distinct, disproving Hoerner's theory.

Choi et al. (5) did not find differences in the morphology of $P$. humuli and P. cubensis, whereas Waterhouse and Brothers (53) and Runge and Thines (38) demonstrated that $P$. cubensis differs morphologically from host to host. Our present results show that sporangia of $P$. humuli and $P$. cubensis are dissimilar on their original hosts but are more similar on the same artificial host.

Table 1. Morphological comparison of Pseudoperonospora humuli on Humulus lupulus and on cucurbitaceous hosts ${ }^{\mathrm{a}}$

\begin{tabular}{lllll}
\hline & \multicolumn{4}{c}{ Pseudoperonospora humuli } \\
\cline { 2 - 6 } Pathogen host species & \multicolumn{1}{c}{ Humulus lupulus } & \multicolumn{1}{c}{ Bryonia dioica } & \multicolumn{1}{c}{ Sicyos angulatus } & Cucumis sativus \\
\hline Sporangiophores & & & & \\
Sporangiophore length & $(160-) 207-253-300(-392)$ & $(157-) 223-262-306(-385)$ & $(119-) 190-295-344(-391)$ & $(161-) 188-251-284(-360)$ \\
Height, first branching & $(106-) 167-195-222(-297)$ & $(107-) 137-199-230(-272)$ & $(94.2-) 133-203-240(-270)$ & $(94.9-) 148-183-221(-241)$ \\
Ram. length/height $\mathrm{b}$ & $(1.13-) 1.27-1.31-1.48(-1.60)$ & $(1.16-) 1.24-1.33-1.39(-1.67)$ & $(1.22-) 1.37-1.45-1.60(-1.76)$ & $(1.19-) 1.32-1.38-1.62(-1.70)$ \\
Width of trunk & $(3.86-) 4.46-4.89-5.21(-6.34)$ & $(3.28-) 4.42-5.00-5.84(-6.84)$ & $(3.26-) 5.46-5.81-6.55(-8.51)$ & $(3.49-) 3.96-4.20-4.56(-5.32)$ \\
Branching times & $3-6$ orders & $3-6$ orders & $3-7$ orders & $3-6$ orders \\
Ultimate branchlets & & & & \\
$\quad$ Length (longer) & $(6.85-) 8.75-11.9-14.1(-21.8)$ & $(6.67-) 9.86-11.8-15.2(-22.3)$ & $(4.95-) 7.62-10.2-13.4(-18.4)$ & $(7.34-) 9.43-11.4-14.2(-21.0)$ \\
Length (shorter) & $(4.19-) 6.96-9.44-11.4(-15.6)$ & $(4.42-) 7.80-9.37-11.9(-19.7)$ & $(4.00-) 6.81-8.48-11.0(-17.5)$ & $(4.93-) 8.26-9.69-13.5(-18.9)$ \\
Longer/shorter ratio & $(1.00-) 1.16-1.28-1.55(-1.86)$ & $(1.04-) 1.18-1.27-1.44(-1.56)$ & $(1.00-) 1.10-1.20-1.40(-1.65)$ & $(1.01-) 1.08-1.20-1.30(-1.63)$ \\
Sporangia & & & & \\
$\quad$ & & & & \\
Length & $(17.0-) 21.8-23.7-26.2(-36.2)$ & $(18.5-) 22.1-24.1-27.7(-32.7)$ & $(17.0-) 19.7-21.6-23.2(-26.3)$ & $(16.3-) 20.1-21.6-25.2(-31.7)$ \\
Width & $(11.2-) 13.6-15.0-16.5(-21.0)$ & $(11.8-) 13.8-15.0-16.8(-18.5)$ & $(11.7-) 13.1-13.8-14.5(-17.0)$ & $(11.2-) 13.5-15.2-16.9(-20.5)$ \\
Length/width ratio & $(1.23-) 1.44-1.59-1.75(-2.09)$ & $(1.23-) 1.50-1.61-1.77(-2.26)$ & $(1.22-) 1.45-1.56-1.68(-1.90)$ & $(1.19-) 1.35-1.43-1.53(-2.00)$ \\
\hline
\end{tabular}

a All measurements given in the form (minimum-) border of 30\%-mean-border of 30\% (-maximum). All values are rounded to three counting digits.

${ }^{\mathrm{b}}$ Ratio length to height of the first ramification.

Table 2. Morphological comparison of Pseudoperonospora cubensis on Humulus lupulus and on cucurbitaceous hosts ${ }^{\mathrm{a}}$

\begin{tabular}{|c|c|c|c|c|}
\hline \multirow[b]{2}{*}{ Pathogen host species } & \multicolumn{4}{|c|}{ Pseudoperonospora cubensis } \\
\hline & Cucumis sativus & Bryonia dioica & Sicyos angulatus & Humulus lupulus ${ }^{\mathrm{b}}$ \\
\hline \multicolumn{5}{|l|}{ Sporangiophores } \\
\hline Sporangiophore length & $(173-) 263-325-376(-518)$ & $(224-) 259-365-412(-530)$ & $(246-) 292-407-458(-584)$ & $\ldots$ \\
\hline Height, first branching & $(101-) 168-236-273(-387)$ & $(130-) 194-272-310(-394)$ & $(189-) 218-306-343(-495)$ & $\ldots$ \\
\hline Ram. length/height ${ }^{\mathrm{c}}$ & $(1.18-) 1.28-1.41-1.65(-1.91)$ & $(1.22-) 1.31-1.36-1.92(-1.92)$ & $(1.07-) 1.24-1.33-1.41(-1.55)$ & $\ldots$ \\
\hline Width of trunk & $(3.07-) 4.64-5.34-6.47(-7.15)$ & $(3.57-) 4.61-5.39-6.70(-7.54)$ & $(2.88-) 3.40-4.01-4.52(-5.32)$ & $\ldots$ \\
\hline Branching times & $3-6$ orders & $3-6$ orders & $3-7$ orders & $\ldots$ \\
\hline \multicolumn{5}{|l|}{ Ultimate branchlets } \\
\hline Length (longer) & $(3.99-) 7.08-9.38-12.2(-15.2)$ & $(5.63-) 8.01-10.4-13.6(-18.0)$ & $(3.98-) 7.57-9.75-14.7(-18.7)$ & $\ldots$ \\
\hline Length (shorter) & $(2.93-) 5.57-7.31-9.62(-13.7)$ & $(4.91-) 6.63-8.49-11.7(-14.5)$ & $(2.45-) 5.96-7.75-12.8(-17.1)$ & $\ldots$ \\
\hline Longer/shorter ratio & $(1.01-) 1.17-1.32-1.53(-2.23)$ & $(1.00-) 1.14-1.24-1.37(-1.89)$ & $(1.01-) 1.14-1.30-1.71(-2.11)$ & $\ldots$ \\
\hline \multicolumn{5}{|l|}{ Sporangia } \\
\hline Length & $(17.0-) 22.6-24.8-27.9(-36.9)$ & $(17.9-) 22.1-23.6-25.8(-33.8)$ & $(17.3-) 20.3-22.1-23.5(-30.5)$ & $\ldots$ \\
\hline Width & $(12.5-) 15.6-17.4-19.2(-25.1)$ & $(11.9-) 14.9-15.7-17.7(-21.5)$ & $(12.7-) 14.6-15.6-16.6(-19.2)$ & $\ldots$ \\
\hline Length/width ratio & $(1.18-) 1.34-1.43-1.54(-1.78)$ & $(1.30-) 1.40-1.51-1.60(-1.81)$ & $(1.20-) 1.34-1.41-1.47(-1.58)$ & $\ldots$ \\
\hline
\end{tabular}

${ }^{a}$ All measurements given in the form (minimum-) border of 30\%-mean-border of 30\% (-maximum). All values are rounded to three counting digits.

${ }^{\mathrm{b}}$ No measurements available, because of too sparse sporulation.

${ }^{\mathrm{c}}$ Ratio length to height of the first ramification. 
Sporangia of $P$. humuli were usually more oblong than sporangia of $P$. cubensis but sporangia of $P$. humuli on $H$. lupulus measured by Arens (1) were rounder in shape compared with the measurements of this study, and the sporangia of $P$. humuli on $C$. sativus were, in shape, statistically not different from sporangia of $P$. cubensis on $C$. sativus. Although there are statistical differences in the morphology of $P$. cubensis and $P$. humuli, it is hardly possible to distinguish the pathogens on the same host species. Taking into account the dependence of the morphology on the host matrix as demonstrated for $P$. cubensis (38), morphological determination without taking the host into account is not feasible. However, contrary to the observations of Choi et al. (5), we could distinguish $P$. humuli and $P$. cubensis on their original hosts. The only characteristics which allowed distinguishing without taking into account the host matrix were the length of the sporangiophores and the height of the first ramification. However, the present study was conducted under controlled conditions and morphology of the pathogen is depended on temperature, humidity, and affected host organ $(14,15,23)$, leading to higher variation of the characteristics under natural conditions. In addition, to ensure that the differences observed follow a general pattern, several more isolates of either species had to be sampled. Probably Choi et al. (5) could not find differences between $P$. humuli and $P$. cubensis because the measurements were taken of material from outdoors and, therefore, environmental conditions impacted sporangia and sporangiophore morphology to a degree making it impossible to infer statistically supported differences. Therefore, a differentiation of naturally occurring diseases caused by $P$. cubensis and $P$. humuli seems not feasible. Also, in Peronospora and Hyaloperonospora spp., it is often difficult to distinguish species on the basis of morphology $(20,51)$. However, morphological crypticness does not preclude species from being evolutionarily separated, thus constituting different taxa. Several molecular phylogenetic investigations $(6,7,17,33,49)$ have recently revealed that several Peronospora spp. Are, indeed, complexes of phylogenetically distinct species.

Even though the morphological differentiation of species in the $P$. cubensis species complex is probably impossible, the molecular phylogenetic investigation of Runge et al. (36) provides evidence for the existence of at least four phylogenetically distinct lineages within this complex, of which two had previously not been recognized. Two of these lineages were found occurring on Cucurbitaceae species and, thus, pathogens subsumed under $P$. cubensis represent two distinct phylogenetic lineages that might constitute different subspecies or even species. Only one strain of one of these lineages could be tested in this study and further studies are warranted to determine the infection potential of both lineages using several strains. However, the results of the parallel study of Mitchell et al. (31) in conjunction with this study show that geographically divergent strains of $P$. cubensis and $P$. humuli are able to reproduce asexually on the hosts of the other pathogen. Unfortunately, Mitchell et al. (31) did not confirm the identity of the single sporangiophore of $P$. humuli they observed on cucumber during their infection trials by sequencing or back infection. The strain of $P$. humuli used in the current study seemed to more readily infect cucumber, because infections were observed in 7 of 25 trials in our study. At the same time, the strain of $P$. cubensis used in this study less readily infected hops, with successful infections in only 6 of 25 trials. It is likely that, using other host strains and pathotypes, the outcome of the infection trials might differ from the present results, with both more and less virulent strains and more or less resistant hosts. However, the successful cross-inoculations reported in this study demonstrate that, apparently, the host jump across orders is still not concluded, with limited infection potential still being present on the hosts of the other species for the isolates used in this study. This host jump most likely did not occur from Cucurbitaceae to hops, as assumed by Mitchell et al (31) without presenting data supporting this scenario, but more likely occurred from hop to Cucurbitaceae, as made evident by Runge et al. (36), who could gain support for a basal position of Pseudoperonospora from two hop species. This scenario might also be more plausible because, except for $P$. cubensis, all species of Pseudoperonospora are parasitic to members of the Rosales. The relatively easy infestation of the cucurbits with $P$. humuli is noteworthy and future studies will be necessary to clarify which characteristics of hop led to a preadaptation on a very wide range of Cucurbitaceae species. The morphological malformation of $P$. cubensis on $H$. lupulus could be indicative of a loss or evolutionary degradation of effectors required for colonization of hop during the adaptation to the new host, thus leading to less efficient colonization and nutrient uptake on the former host. In fact, this evolutionary process could be the reason for the species richness of downy mildews and other specialized obligate biotrophic pathogens, because loss of virulence on the original hosts as a result of the cost for optimal adaptation to a new host will lead to reduced gene flow and, eventually, genetic isolation and speciation. It is plausible that, after the host jump, additional specialization occurred, which is apparent from the different pathotypes present in $P$. cubensis $(29,50)$. The processes leading to a host jump are not well understood thus far. New species are thought to emerge in adaption to geographically available plants and these are often not the closest relatives of the original host (34). However, even considering that these hosts might not have been able to evolve specific defense mechanisms, a prerequisite for the successful colonization of a new host is the successful suppression of basal defense. The effectors responsible for this suppression are likely to perform less well on targets of more distantly related hosts because, in general, target protein divergence will increase with phylogenetic distance. This is corroborated by Gilbert and Webb (18), who came to the conclusion that susceptibility of different plant species to a specific pathogen decreases with phylogenetic distance. It might also be speculated that similar physiological lifestyles might ease a host shift; for example, Peronosclerospora spp. exclusively occur on only distantly related $\mathrm{C} 4$ grasses (25) and P. cubensis and $P$. humuli both occur on vines. However, further evidence is required to support this hypothesis.

Because $P$. humuli has an extraordinary infection potential in laboratory experiments (21), it seems probable that more lines of this pathogen with greater virulence on members of Cucurbitaceae might be present or be arising, and that these lines might result in destructive diseases, especially if some limited potential to exchange genetic material between $P$. cubensis and $P$. humuli still exists.

The potential of $P$. cubensis to infect the perennial species $H$. lupulus (31, this study) and B. dioica (37), and also the recent finding of Cohen et al. (9) that oospores are formed abundantly if two compatible genotypes are brought together, necessitates careful reaffirmation that long-range dispersal by wind from southern regions (22) is the only naturally occurring source of primary infections. However, unless genotypes of hop allowing for more efficient colonization of $P$. cubensis are found, the malformation of $P$. cubensis on $H$. lupulus, and lower infection rates observed in a parallel study (31), which indicate a lack of nourishment, raise some doubts regarding the overwintering of the P. cubensis mycelium in this host. Further screens of hop germplasm and natural infections occurring on hop are necessary to determine the risk of overwintering of $P$. cubensis in rhizomes of hop.

\section{Acknowledgments}

This study was first submitted in January 2011 and was supported by a grant from the Ministry of Science, Education, and the Arts of Baden-Württemberg awarded to F. Runge and by the research funding program "LOEWE-LandesOffensive zur Entwicklung Wissenschaftlich-ökonomischer Exzellenz" of Hess's Ministry of Higher Education, Research, and the Arts. We thank O. Spring for providing laboratory and climate chamber space for conducting the experiments and A. Lebeda for providing the laboratory strain of $P$. cubensis.

\section{Literature Cited}

1. Arens, K. 1929. Untersuchungen über Pseudoperonospora humuli (Miyabe u. Takah.), den Erreger der neuen Hopfenkrankheit. Phytopathol. Z. 1:169-193.

2. Bains, S. S., and Jhooty, J. S. 1976. Over wintering of Pseudoperonospora cubensis causing downy mildew of muskmelon. Indian Phytopathol. 29:213-214. 
3. Berg, C. C. 1977. Urticales, their differentiation and systematic position. Plant Syst. Evol. 1:169-193.

4. Bremer, K., Chase, M. W., and Stevens, P. F. 1998. An ordinal classification of the families of flowering plants. Ann. Mo. Bot. Gard. 85:531-553.

5. Choi, Y.-J., Hong, S.-B., and Shin, H.-D. 2005. A re-consideration of Pseudoperonospora cubensis and $P$. humuli based on molecular and morphological data. Mycol. Res. 109:841-848.

6. Choi, Y.-J., Hong, S.-B., and Shin, H.D. 2007. Re-consideration of Peronospora farinosa infecting Spinacia oleracea as distinct species, Peronospora effusa. Mycol. Res. 110:381-391.

7. Choi, Y.-J., Shin, H.-D., and Thines, M. 2009. Two novel Peronospora species are associated with recent reports of downy mildew on sages. Mycol. Res. 113:1340-1350.

8. Cohen, Y. 1981. Downy mildew of cucurbits. Pages 341-354 in: The Downy Mildews. D. M. Spencer, ed. Academic Press, London.

9. Cohen, Y., Rubin, A. E., Galperin, M. 2011. Formation and infectivity of oospores of Pseudoperonospora cubensis, the causal agent of downy mildew in cucurbits. Plant Dis. 95:874.

10. Coley-Smith, J. R. 1965. Infection of hop rootstocks by downy mildew Pseudoperonospora humuli (Miy. et Tak.) Wilson and its control by earlyseason dusts. Ann. Appl. Biol. 56:381-388.

11. Constantinescu, O. 2000. The fine structure of the sporangium in Pseudoperonospora humuli (Chromista, Oomycota, Peronosporales). Cryptogam. Mycol. 21:93-101.

12. Constantinescu, O., and Fatehi, J. 2002. Peronospora-like fungi (Chromista, Peronosporales) parasitic on Brassicaceae and related hosts. Nova Hedwigia 74:291-338.

13. Cooke, D. E. L., Drenth, A., Duncan, J. M., Wagels, G., and Brasier, C. M. 2000. A molecular phylogeny of Phytophthora and related oomycetes. Fungal Genet. Biol. 30:17-32.

14. Delanoe, D. 1972. Biologie et Epidemiologie du mildiou du tournesol. CETIOM Inf. Tech. 26:1-61.

15. Dudka, I. O., Anishchenko, I. M., and Terent'eva, N. G. 2007. The variability of Peronospora alta Fuckel conidia in dependence on the ecological conditions. Pages 39-46 in: Advances in Downy Mildew Research, vol. 3. A. Lebeda and P. T. N. Spencer-Phillips, eds. Palacký University in Olomouc and JOLA, v.o.s., Kostelec na Hané, Czech Republic.

16. Fraymouth, J. 1956. Haustoria of the Peronosporales. Trans. Br. Mycol. Soc. 39:79-107.

17. García-Blázquez, G., Göker, M., Voglmayr, H., Martín, M. P., Tellería, M. T., and Oberwinkler, F. 2008. Phylogeny of Peronospora, parasitic on Fabaceae, based on ITS sequences. Mycol. Res. 112:502-512.

18. Gilbert, G. S., and Webb, C. O. 2007. Phylogenetic signal in plant pathogen-host range. Proc. Natl. Acad. Sci. USA 104:4979-4983.

19. Glazewska, Z. 1971. The host plants of the fungus Pseudoperonospora humuli (Miy. et Takah.). Pamietnik Pulawski 49:191-204.

20. Göker, M., Voglmayr, H., García-Blázquez, G., and Oberwinkler, F. 2009. Species delimitation in downy mildews: the case of Hyaloperonospora in the light of nuclear ribosomal ITS and LSU sequences. Mycol. Res. 113:308-325.

21. Hoerner, G. F. 1940. The infection capabilities of hop downy mildew. J. Agric. Res. 61:331-334.

22. Holmes, G. J., Main, C. E., and Keever, III, Z. T. 2004. Cucurbit downy mildew: a unique pathosystem for disease forecasting. Pages 69-80 in Advances in Downy Mildew Research, vol. 2. P. T. N. Spencer-Phillips and M. Jeger, eds. Kluwer, Dordrecht, The Netherlands.

23. Iwata, Y. 1942. Specialization in Pseudoperonospora cubensis (Berk. et Curt.) Rostov. II. Comparative studies of the morphologies of the fungi from Cucumis sativus L. and Cucurbita moschata Duchesne. Ann. Phytopathol. Soc. Jpn. 11:172-185.

24. Johnson, D. A., and Anliker, W. L. 1985. Effect of downy mildew epidemics on the seasonal carryover of initial inoculum in hop yards. Plant Dis. 69:140-142.

25. Kenneth, R. G. 1981. Downy mildews of graminaceous crops. Pages 367394 in: The Downy Mildews. D. M. Spencer, ed. Academic Press, London.

26. Kirk, P. M., Cannon, P. F., David, J. C., and Stalpers, J. A. 2001. Ainsworth and Bisby's Dictionary of the Fungi, 9th ed. CAB International, Wallingford, UK.

27. Lebeda, A. 1990. Biology and ecology of cucurbit downy mildew. Pages 13-46 in: Cucurbit downy mildew. A. Lebeda, ed. Czechoslovak Scientific Society for Mycology by Czechoslovak Academy of Sciences, Prague.

28. Lebeda, A. 1999. Pseudoperonospora cubensis on Cucumis spp. and Cucurbita spp.—resistance breeding aspects. Acta Hortic. 492:363-370.

29. Lebeda, A., and Widrlechner, M. P. 2003. A set of Cucurbitaceae taxa for differentiation of Pseudoperonospora cubensis pathotypes. J. Plant Dis. Prot. 110:337-349.

30. Mann, H., and Whitney, D. 1947. On a test of whether one of two random variables is stochastically larger than the other. Ann. Math. Stat. 18:50-60.

31. Mitchell, M. N., Ocamb, C., Grünwald, N. J., Mancino, L. E., and Gent, D. 2011. Genetic and Pathogenic Relatedness of Pseudoperonospora cubensis and $P$. humuli. Phytopathology 101:805-818.

32. Moncalvo, J. M., Wang, H. H., and Hseu, R. S. 1995. Phylogenetic relationships in Ganoderma inferred from the internal transcribed spacers and $25 \mathrm{~S}$ ribosomal DNA sequences. Mycologia 87:223.

33. Riethmüller, A., Voglmayr, H., Göker, M., Weiß, M., and Oberwinkler, F. 2002. Phylogenetic relationships of the downy mildews (Peronosporales) and related groups based on nuclear large subunit ribosomal DNA sequences. Mycologia 94:834-849.

34. Roy, B. A. 2001. Patterns of association between crucifers and their flowermimic pathogens: host jumps are more common than coevolution or cospeciation. Evolution 55:41-53.

35. Royle, D. J., and Kremheller, H. T. H. 1981. Downy mildew of the hop Pages 395-419 in: The Downy Mildews. D. M. Spencer, ed. Academic Press, London.

36. Runge, F., Choi, Y.-J., and Thines, M. Phylogenetic investigations in the genus Pseudoperonospora reveal overlooked species and cryptic diversity in the $P$. cubensis species cluster. Eur. J. Plant Pathol. In press.

37. Runge, F., and Thines, M. 2009. A potential perennial host for Pseudoperonospora cubensis in temperate regions. Eur. J. Plant Pathol. 123:483486.

38. Runge, F., and Thines, M. Host matrix has major impact on the morphology of Pseudoperonospora cubensis. Eur. J. Plant Pathol. In press.

39. Salmon, E. S., and Ware, W. M. 1925. On the presence of a perennial mycelium in Pseudoperonospora humuli (Miyabe \& Takah.) Wils. Nature 116:134-135.

40. Salmon, E. S., and Ware, W. M. 1928. Inoculation experiments with the downy mildews of the hop and nettle (Pseudoperonospora humuli (Miy. et Takah.) Wils. and P. urticae (Lib.) Salm. et Ware). Ann. Appl. Biol. 15:352370 .

41. Salmon, E. S., and Ware, W. M. 1929. Two downy mildews of the nettle: Pseudoperonospora urticae (Lib.) Salm. et Ware and Peronospora debaryi nomen novum. Trans. Br. Mycol. Soc. 14:38-60.

42. Shin, H.-D., and Choi, Y.-J. 2003. A first check-list of Peronosporaceae from Korea. Mycotaxon 86:249-267.

43. Skotland, C. B. 1961. Infection of hop crowns and roots by Pseudoperonospora humuli and its relation to crown and root rot and overwintering of the pathogen. Phytopathology 51:241-244.

44. Soltis, D. E., Soltis, P. S., Nickrent, D. L., Johnson, L. A., Hahn, W. J., Hoot, S. B., Sweere, J. A., Kuzoff, R. K., Kron, K. A., Chase, M. W., Swensen, S. M., Zimmer, E. A., Chaw, S. M., Gillespie, L. J., Kress, W. J., and Systma, K. J. 1997. Angiosperm phylogeny inferred from 18 S ribosomal DNA sequences. Ann. Mo. Bot. Gard. 84:1-49.

45. Song, B. H., Wang, X. Q., Li, F. Z., and Hong, D. Y. 2001. Further evidence for paraphyly of the Celtidaceae from the chloroplast gene matK. Plant Syst. Evol. 228:107-115.

46. Tamura, K., Dudley, J., Nei, M., and Kumar, S. 2007. MEGA4: Molecular Evolutionary Genetics Analysis (MEGA) software version 4. Mol. Biol. Evol. 24:1596-1599.

47. Thines, M. 2006. Evaluation of characters available from herbarium vouchers for the phylogeny of the downy mildew genera (Chromista, Peronosporales), with focus on scanning electron microscopy. Mycotaxon 97:195-218.

48. Thines, M. 2007. Characterisation and phylogeny of repeated elements giving rise to exceptional length of ITS2 in several downy mildew genera (Peronosporaceae). Fungal Genet. Biol. 44:199-207.

49. Thines, M., Voglmayr, H., and Göker, M. 2009. Taxonomy and phylogeny of the downy mildews (Peronosporaceae). Pages 47-75 in: Oomycete Genetics and Genomics: Diversity, Interactions, and Research Tools. K. Lamour and S. Kamoun, eds. Wiley-VCH, Weinheim, Germany.

50. Thomas, C. E., Inaba, T., and Cohen, Y. 1987. Physiological specialization in Pseudoperonospora cubensis. Phytopathology 77:1621-1624.

51. Voglmayr, H. 2003. Phylogenetic relationships of Peronospora and related genera based on nuclear ribosomal ITS sequences. Mycol. Res. 107:1132 1142

52. Voglmayr, H., Piatek, M., and Mossebo, D. C. 2009. Pseudoperonospora cubensis causing downy mildew disease on Impatiens irvingii in Cameroon: a new host for the pathogen. Plant Pathol. 58:394.

53. Waterhouse, G. M., and Brothers, M. P. 1981. The taxonomy of Pseudoper onospora. Mycol. Pap. 148:1-28. 